\title{
Feasibility of Machine-Based Prompting to Assist Persons With Dementia
}

\author{
Megan Witte Bewernitz PhD OTR/L, William C. Mann PhD OTR, Patricia \\ Dasler MA OTR/L \& Patrícia Belchior PhD OT
}

To cite this article: Megan Witte Bewernitz PhD OTR/L , William C. Mann PhD OTR, Patricia Dasler MA OTR/L \& Patrícia Belchior PhD OT (2009) Feasibility of Machine-Based Prompting to Assist Persons With Dementia, Assistive Technology, 21:4, 196-207, DOI: 10.1080/10400430903246050

To link to this article: https://doi.org/10.1080/10400430903246050

册 Published online: 13 Nov 2009.

Submit your article to this journal $\pi$

山 Article views: 740

Q View related articles $\sqsubset$

4 Citing articles: 18 View citing articles 


\section{Feasibility of Machine-Based Prompting to Assist Persons With Dementia}

\author{
Megan Witte Bewernitz, \\ $\mathrm{PhD}, \mathrm{OTR} / \mathrm{L},{ }^{1}$ William \\ C. Mann, PhD, OTR, ${ }^{1}$ Patricia \\ Dasler, MA, OTR/L, ${ }^{2}$ and \\ Patrícia Belchior, PhD, OT $^{1}$ \\ ${ }^{1}$ Department of Occupational \\ Therapy, University of Florida, \\ Gainesville, Florida \\ ${ }^{2}$ Special Communications, LCC, \\ Gainesville, Florida
}

\begin{abstract}
Nearly 14\% of people over age 71 have some form of dementia, with prevalence increasing to nearly $40 \%$ of those over age 90 . As dimentia progresses, it impacts a person's independent functions and can increase the burden on caregivers. The use of assistive devices can help individuals with dementia live more independently. However, older individuals with cognitive impairment have difficulties using assistive technology devices because the devices are not designed to address their needs. The development of "smart devices" has potential in assisting older adults with cognitive impairment. Eleven community-dwelling seniors with moderate cognitive impairment (Mini-Mental State Examination scores ranging from 12-20) participated in this study. The Functional Independence Measure scores of participants were also collected to determine participants' current level of independence on selected tasks. Three tasks were selected to represent three levels of complexity: drinking water, brushing teeth, and upper body dressing. Participants were prompted through these tasks with simulated smart machine-based prompting. The need for prompts was highly individual, but given appropriate machine-delivered messages, participants completed the tasks an average of $86 \%$ of the time across the three self-care tasks. Machine-based prompting devices could aid caregivers as well as increase independence in some tasks.
\end{abstract}

KEYWORDS aging, dementia, independence, machine-based prompting device, smart technology

\section{INTRODUCTION}

Nearly $14 \%$ of people over age 71 have some form of dementia, with the prevalence increasing to nearly $40 \%$ of those over age 90 (Plassman et al., 2007). Dementia is a broad term to describe a decline in intellectual functioning that is not a normal aspect of the aging process (Cummings, 1984; Glickstein, 1997). Alzheimer's disease is the leading cause of dementia in persons over 65 (National Institute on Aging, 2004), with strokes being the second most frequently occurring cause (Plassman et al., 2007). Twenty percent to $25 \%$ of stroke patients become demented after stroke (Van Kooten \& Koudstaal, 1998).

The major characteristic of Alzheimer's disease is a progressive decline in cognitive function (Mesulam, 2000). With impaired cognitive function, a
Address correspondence to Megan Witte Bewernitz, Department of Occupational Therapy, University of Florida, P.O. Box 100164, Gainesville, FL 32610-0164.

E-mail: mwitte@phhp.ufl.edu 
person may experience confusion, disorientation, limited attention, memory impairment, and decreased ability to learn (Alzheimer's Association, 2007; Poole, Dunn, Schell, \& Barnhart, 1991). Other common symptoms of Alzheimer's disease include language disorders, apraxia, visuoconstructive difficulty, and difficulty with abstract thinking (Pynoos \& Ohta, 1991). As Alzheimer's disease progresses, it impacts functional performance. A person with Alzheimer's disease will decline in ability to meet safety, self-care, household, leisure, social interaction, and vocational needs and ability to perform basic activities of daily living (Abraham, 2006).

Cognitive impairment can impact people's ability to make appropriate judgments and decisions about safe and dangerous situations. For a person with cognitive impairment, it is necessary to provide a simple, safe, and familiar environment (Alzheimer's Disease and Related Disorders Association, 1985; Reimer, Slaughter, Donaldson, Currie, \& Eliasziw, 2004). Suggestions and guidelines for environmental interventions in the living spaces of persons with cognitive impairments are common in the literature (Butin, 1991; Cohen-Mansfield \& Werner, 1998; Gitlin, Corcoran, Winter, Boyce, \& Hauck, 2001; Olsen, Ehrenkrantz, \& Hutchings, 1993; Pynoos \& Ohta, 1991).

\section{Dementia and the Caregiver}

Dementia also impacts family members. Poor health of family members and lack of knowledge or information of the disease process is common (Paton, Johnson, Katona, \& Livingston, 2004; Zarit \& Zarit, 1982). Caring for a patient with dementia is more stressful than caring for a patient without dementia, due to the nature of dementia itself. Caregivers have difficulty in coping with the unpredictable behaviors common in patients with dementia (Lévesque, Ducharme, \& Lachance, 1999; Rowe \& Fehrenbach, 2004). Reducing the burden of care or time spent in the caring role may be one strategy to improve caregiver health. The use of assistive devices, such as a "smart prompting device," could lessen the burden experienced by caregivers of individuals with dementia.

\section{Assistive Devices for Cognitive Impairment}

Elders with cognitive impairment use fewer assistive devices than elders with motor or sensory impairments
(Mann, Karuza, Hurren, \& Tomita, 1993). Elderly persons with cognitive impairment use more devices for physical disabilities than devices that address cognitive impairment. Mild to moderately cognitively impaired persons with higher Mini-Mental State Examination (MMSE) scores (15 to 23 out of 30 ) and their caregivers tend to accept assistive devices more readily than those with lower MMSE scores (10 to 14) (Nochajski, Tomita, \& Mann, 1996). Of those elderly persons with cognitive impairment who do choose to use assistive devices, the devices tend to address physical rather than cognitive impairments.

Assistive devices are typically not designed for people with cognitive impairment, especially those devices that address motor and sensory impairment. Development of "smart" devices that can assist individuals with the cognitive aspect of task completion is just beginning.

Lo Presti, Mihailidis, and Kirsch (2004) reported on the state of the art of assistive technology for cognitive rehabilitation. They found that many assistive devices for cognitive impairment require the user to provide some feedback, such as pushing a button after the cue task has been completed. However, cognitive disability may compromise people's ability to remember which step they have just taken. Context-aware prompting devices or "smart devices" should remediate these problems.

An emerging area of research and development is focused on assisting persons with cognitive impairments in their daily activities through the use of computerized devices (Mihailidis, Fernie, \& Cleghborn, 2000). A computerized system was developed to assist with the task of hand washing for elderly persons with moderate and severe dementia. The system used artificial intelligence (AI) and consisted of a nine-step verbal prompting device equipped with transducers to monitor step completion. It did not require user input or intervention for effective operation. An efficacy study showed that the device was effective in assisting the majority of subjects that participated in the study. There was an improvement in the number of tasks completed without a caregiver. Use of this device reduced the amount of time a caregiver needed to spend with the patient in completing activities of daily living (ADLs) (Mihailidis, Barbenel, \& Fernie, 2004; Mihailidis et al., 2000).

Labelle and Mihailidis (2006) discussed further testing with this device to determine if audio or 
audiovisual cueing was more effective in guiding a person with moderate to severe cognitive impairment through a hand washing task. They used the least prompts approach and "wizard of oz" technology (Doyle, Wolery, Ault, \& Gast, 1988). There was little difference between the use of audiovisual or audioalone prompts in hand washing performance. Caregiver interactions decreased in both prompting scenarios when the subject moved from baseline to intervention phases, with the audiovisual prompting showing statistically fewer interactions.

\section{Use of Prompting for People With Dementia}

In a study of behavioral approaches to improving ADLs in nursing home patients with dementia, use of prompting improved patients' participation and independence in dressing (Rogers et al., 1999). Another study found that a severely cognitively impaired elder improved in activity performance with more nondirective and directive verbal assists rather than physical assists. This study also found that there were more appropriate requests for help when independence was encouraged (Rogers et al., 1999).

Kobayashi and Yamamoto (2004) explored the impact of stage of dementia on the time required for bathing-related care in a nursing home, including time to get to the bath, dressing, and undressing. The focus of this study was on the interaction between the caregiver/care recipient dyad and stage of dementia. Participants were at different stages of dementia and had no serious medical conditions other than severe dementia. While this study found no correlation between stage of dementia and dyad interactions, the dressing aspect of bathing-related care did take longer when caregivers strayed from the person's usual dressing routine. The authors also noted that appropriate use of prompts by the caregiver was associated with efficiency of task completion.

\section{The Cognitive Assistance Device}

The purpose of this study was to explore the feasibility and design of a machine-based prompting system/device for persons with moderate cognitive impairment in the completion of self-care tasks of varied complexity. This study was exploratory in nature and intended to provide direction for future study rather than provide distinct conclusions about machine-based prompting. Tasks were arranged hierarchically by complexity: from a simple "hydration" task (drinking water) to the moderately complex task of brushing teeth and, finally, the complex set of tasks involved in dressing. For each task level, the process toward machine-based assistance began with a person present and moved to simulated machinebased assistance.

Independence in self-care tasks is a major concern for patients with cognitive impairment. Many times, caregivers contribute to loss of functional performance when they "do for" the patients instead of encouraging independence. "Persons with dementia have functional reserves that can be activated when caregivers use levels of assistance, standard, and problem-oriented strategies to support the person's cognitive and physical deficits" (Vagelpohl, Beck, Heacock, \& Mercer, 1996, p. 42). Rogers et al. (1999) demonstrated that a behavioral rehabilitative intervention using cues by caregivers increases independence in self-dressing as well as active participation in other ADLs for nursing home residents with functional disabilities due to cognitive impairment. Supportive interventions by nursing assistants with nursing home residents with cognitive impairment can increase dressing independence of the residents (Beck, Heacock, Mercer, Walls, \& Vogelpohl, 1997).

This study explored (a) basic questions regarding the interface of a device/system to assist elders and their caregivers with daily life tasks and (b) the types of prompts (verbal and visual) that might assist people with cognitive impairment in performing daily living tasks. The goal was to develop guidelines for future research.

\section{METHODS}

The following research questions were addressed regarding use of machine-based prompting by older persons with dementia:

1. Can participants perform complete tasks with machine-delivered prompting?

2. What prompts are needed for each task to ensure quality task performance and safety of the participant? 
3. What aspects of the tasks need to be monitored to provide appropriate prompting?

4. Do participants respond differently to recorded human voice and synthesized voice prompts?

5. Is there an investigator-observed difference in response to verbal versus visual cues?

6. Based on investigator observation, what participants' responses could guide development of machinebased prompting systems for self-care tasks?

\section{Sample}

Eleven community-dwelling seniors with moderate dementia were selected to participate in the study. Participants were recruited following educational programs presented in a variety of caregiver forums, including Alzheimer's support groups. One such presentation was at a center with a day program for seniors with dementia. Following IRB approval, consent to participate was obtained from the both the person with dementia and his or her legal caregiver representative. Participants completed the research protocol following their scheduled center activities. Changes in personal circumstances resulted in some participants discontinuing attendance at the day center. Therefore, the number of participants in each task varied, as did the number of trials completed. Drinking water, the first task, had the largest number of participants and trials (Table 1). MMSE and Functional Independence Measure (FIM) scores, gender, and protocol setting of each study participant were also recorded (Table 2 ).

Three participants demonstrated effects of stroke and used assistive devices for mobility, including a
TABLE 1 Summary of trials by task

\begin{tabular}{lccc}
\hline Task & $\begin{array}{c}\text { Drinking } \\
\text { water }\end{array}$ & $\begin{array}{c}\text { Brushing } \\
\text { teeth }\end{array}$ & $\begin{array}{c}\text { Upperbody } \\
\text { dressing }\end{array}$ \\
\hline $\begin{array}{c}\text { Number of } \\
\text { participants }\end{array}$ & 11 & 7 & 6 \\
Female/male & $7 / 4$ & $6 / 1$ & $3 / 3$ \\
Number of trials & 49 & 16 & 15 \\
\hline
\end{tabular}

motorized chair, walker, and a cane. The participant using the motorized chair had hemiparalysis. The participant using the cane had one-sided weakness. Both of these participants were seen in their homes. The participant using the walker demonstrated poor balance, impulsivity, and inability to control rate and volume of speech.

\section{Instruments}

Cognitive impairment was measured using the MMSE (Folstein, Folstein, \& McHugh, 1975), and those with an MMSE score ranging from 12 to 20 were included in the study. The FIM was used to determine if potential participants needed assistance with eating, grooming, and upper body dressing. The FIM was developed as an instrument to determine severity of disability. It consists of 18 items, each with a maximum score of 7 and a minimum score of 1 . Thus, the highest possible total score is 126 , and the lowest is 18. Each level of scoring (1 through 7) is defined (for example, 7 = "complete independence," $3=$ "moderate assistance"). The FIM measures the following areas: self-care, sphincter control, transfers, locomotion, communication, and social cognition. The FIM has been found to be reliable and valid, even

TABLE 2 MMSE and FIM scores of study participants

\begin{tabular}{lrrrrrrrrrrr}
\hline & \multicolumn{10}{c}{ Participant } \\
\cline { 2 - 12 } & A & B & C & D & E,b & F & G & H & I & J $^{\text {a,b }}$ & K $^{\text {a }}$ \\
\hline MMSE & 12 & 13 & 14 & 15 & 16 & 16 & 18 & 18 & 19 & 19 & 20 \\
FIM eating & 7 & 5 & 7 & 7 & 5 & 7 & 7 & 7 & 7 & 7 & 5 \\
FIM grooming & 7 & 2 & 4 & 7 & 5 & 4 & 7 & 5 & 5 & 5 & 5 \\
FIM upper body dressing & 5 & 3 & 5 & 5 & 5 & 4 & 5 & 6 & 5 & 3 & 4 \\
Gender & F & M & F & F & M & M & F & F & F & F & M \\
\hline
\end{tabular}

Note. FIM scores are averages per caregiver reports.

aParticipants with effects of stroke.

barticipants seen in their homes. 
with subjects over age 80 (Fricke, Unsworth, \& Worrell, 1993). FIM item scores for grooming, upper extremity dressing, and lower extremity dressing were used in this study. Scores were determined based on caregiver reports.

\section{Protocol}

Three self-care tasks were selected to represent three levels of complexity: drinking water, brushing teeth, and upper body dressing. These tasks also vary in level of privacy associated with them. The drinking water task was the least complex and least personal. The dressing task was the most complex and most personal. Two clients who had hemiparesis from strokes were seen in their home, which provided a familiar environment and permitted research staff the opportunity to observe the distractions and barriers presented in each unique home environment. Nine participants were seen at one of two day centers.

For each task, there were three different conditions under which the task was prompted. In Condition 1, the participant was first asked to perform the task in the presence of the investigator. This situation allowed the investigator to assist with problems that might come up for drinking water, such as where the glasses are kept, by providing verbal cues. Further, it allowed the investigator to determine if new cues would need to be developed to assist individual participants. This was important for the trials conducted in the home situation. In one home situation drinking glasses were stored out of sight in a cupboard, and in the other the participant had to maneuver her motorized chair to the refrigerator door to obtain ice and water. However, in the day centers where the task environment was the same for all participants, the task became standardized and the need for direct observation was not necessary. In Condition 2, an intercom was used to deliver "live" cues while the participant was observed through a remote camera. This allowed the use of cues documented during direct observation sessions as well any necessary new cues. In Condition 3, prerecorded human voice, synthesized voice, or visual prompts were presented. The visual prompts were accompanied by verbal prerecorded cues. Cues were given judiciously by the investigator, either when progress toward the task goal was not being accomplished or when there was a safety concern.

\section{Environmental Set-Up}

There were two "areas" for each task, the participant task area and the observer's area. In the participant task area, there was a wireless camera with microphone and a system to deliver cues. The camera allowed for remote observation of the participant during task performance. It was remotely controlled to allow the investigator to move it to follow the movements of the participant during the task. The task area also included a method to deliver the cues depending on the task and trial condition, an intercom, wireless speakers, or a monitor with built-in speakers. Objects for each of the tasks were provided at the day center or found within the environment in the home situation.

In the observer's area, there were intercoms or a laptop with prerecorded cues for cueing the participant. There was a monitor with a live feed from the camera in the participant area. This allowed the observer to see and hear the participant remotely. In this way, a simulated "smart environment" was created. Rather than an aware environment with an array of sensors to perceive participant performance, the investigators observed the behavior from another location and delivered prompts for the behavior as appropriate.

\section{Hydration Task}

For the hydration task, the participant was asked to drink water, with a goal of drinking at least 4 ounces. Trials conducted in participants' homes began with the participant in a typical situation for that time of day, such as in the living room watching TV. These participants were asked to go to the kitchen, obtain a glass, fill it with water, and consume at least 4 ounces. The participants at the day centers were seated in a quiet area apart from the other clients. In one day center, this area was furnished like a living room, and in the other day center a small outside patio was used. A pitcher of water and a glass were located across the room from where the participant was seated. There were other objects, such as a coffee maker, in the room to provide some distraction.

\section{Oral Care}

For the oral care task, participants were asked to brush their teeth or clean their dentures, with the goal 
of cleaning all surfaces of their teeth or dentures, including the chewing surface in the back, the inside or lingual aspect of the teeth, and the outside or buccal aspect. Additionally, they were asked to rinse their mouth and dentures if appropriate and wipe their face and hands. There was some concern that the directions for the places to be brushed could be too complex for verbal instruction (e.g., "on the bottom brush the back on the outside"), so drawings, photos, and videos were prepared to provide visual cues. These graphics were paired with the appropriate verbal cue and displayed on a flat panel monitor with speakers. The flat panel monitor was set up on the countertop to the right of the sink.

\section{Dressing}

The third task included "donning a shirt" for the male participants and "donning a sweater or jacket" for the female participants. One participant was seen in the home environment, and the others were seen in the day centers. The goal of this task was for the participant to don an upper body piece of clothing and finish the task with collar turned down, shirt tucked in (men only), and appropriate buttons buttoned (top buttons could remain open). The investigator asked the participant to remove the piece of clothing. The shirts were folded and placed on a chair. Jackets and sweaters were draped over the arm of the chair. The investigator left the room and instructed the participant to follow the directions given. There were three conditions for cues: intercom, prerecorded voice, and male synthesized voice (no female voice was used, based on previous participant preferences for male voice).

\section{Data Collection and Analysis}

The data included counts of numbers and type of cues with comments for each task. When a message was used, the behavioral response was coded as "correct" response, "no" response, or "repeated." Observers' comments provided additional information or explained no response or an alternate response. Data analysis consisted of compiling the frequency counts per individual participant and by task. Means were calculated from these counts, and the data were reviewed for possible trends.

\section{RESULTS Research Question 1}

FIM scores for eating indicated that all but three participants were independent. The FIM score does include criteria about independently getting something to drink. Caregivers were questioned as to whether the participants initiated getting a drink of some kind during the day. One stated that the participant would occasionally initiate getting a drink. The other caregivers indicated the participants did not initiate getting a drink at home or at the day center. Although not specifically asked, coaxing to finish a beverage was also mentioned. Participants were able to follow prompts issued by the machine to drink at least 4 ounces of water on $85.7 \%$ (43 out of 49 ) of the trials. One participant was unsuccessful in three out of eight trials because she was dependent for toileting and worried that she might not have assistance available if she drank too much. Another participant was unsuccessful in three out of six trials because she did not respond to the initial start directive. This participant was able to respond appropriately to other messages during the trial, once started.

Scores on the FIM for grooming ranged from 4 (minimal assistance) to 7. As previously discussed, these scores were based on caregiver reports. The brushing teeth task was performed completely on $88 \%$ (15 out of 17) of the trials with the assistance of "automated" cues. There was a need for intervention in two trials: One was to locate the toothbrush, and the other was to remove the cap from the toothpaste.

The upper body dressing task FIM scores ranged from 3 to 5 , indicating moderate assistance to supervision. This task was completed with machine-based cues on $80 \%$ (12 out of 15 ) of trials. In one unsuccessful trial, the participant tried to match jacket snaps with blouse buttons, so observer intervention was needed to line up the snaps. In the other instance, the participant did not button his polo shirt. When questioned about this after the trial, he told the observer he did not like the shirt buttoned. In the third incident, a participant neglected the prompt to turn down the collar in back despite repeated task directives to do so.

\section{Research Question 2}

Initially it was anticipated that only task directives would be used. However, it was soon discovered that 
participants would attempt to interact with the system by asking questions. Sometimes it was difficult to determine if participants intended to drink more, as they would stand for a while without moving. A variety of prompts were developed to assist the participant in task completion. Table 3 presents the prompts used for the drinking water task.

A basic request to perform the task or "start directive" was the start point for each trial. However, the sight of objects for tasks seemed to prime task behavior. In several cases, participants began to brush their teeth after seeing the toothbrush before the cue was delivered. Task directives that covered an array of potential errors or task steps such as missing a spot to brush or turning down a collar were needed. Task

\section{TABLE 3 Cue descriptions}

\begin{tabular}{|c|c|c|}
\hline Type of cue & Description & Example \\
\hline Start directive & $\begin{array}{c}\text { Short instruction to } \\
\text { perform the task }\end{array}$ & $\begin{array}{l}\text { It is time to take } \\
\text { a drink of } \\
\text { water. }\end{array}$ \\
\hline Directive & $\begin{array}{l}\text { Short instructions } \\
\text { given to promote } \\
\text { task completion }\end{array}$ & $\begin{array}{c}\text { Make it a nice } \\
\text { big drink. }\end{array}$ \\
\hline Compliment & $\begin{array}{l}\text { Statements to mark } \\
\text { the end of the task } \\
\text { or to offer an } \\
\text { affirmation upon } \\
\text { task completion }\end{array}$ & Good for you. \\
\hline Answer & $\begin{array}{l}\text { Developed to } \\
\text { respond to } \\
\text { questions asked by } \\
\text { the participants } \\
\text { during the task } \\
\text { such as "Is this } \\
\text { enough water?" }\end{array}$ & $\begin{array}{c}\text { Yes, that is } \\
\text { enough. }\end{array}$ \\
\hline Query & $\begin{array}{l}\text { Question asked of } \\
\text { participants to } \\
\text { determine their } \\
\text { intention }\end{array}$ & $\begin{array}{l}\text { Are you } \\
\text { finished? }\end{array}$ \\
\hline Safety directive & $\begin{array}{l}\text { Instructions given for } \\
\text { the purpose of } \\
\text { increasing } \\
\text { participant safety }\end{array}$ & $\begin{array}{l}\text { You can sit } \\
\text { down. }\end{array}$ \\
\hline General cue & $\begin{array}{l}\text { An instruction that } \\
\text { would help the } \\
\text { participant to } \\
\text { determine if the } \\
\text { task was } \\
\text { completed; only } \\
\text { used in the } \\
\text { dressing task }\end{array}$ & $\begin{array}{l}\text { Check your } \\
\text { appearance in } \\
\text { the mirror. }\end{array}$ \\
\hline
\end{tabular}

directives delivered to assist task performance varied not only among participants but also among the trials of the same participant. For example, the directive to turn down a collar was not needed for some participants, was needed only once for another participant, and was needed in every trial for still another participant. In the brushing teeth task, additional messages to deal with the situations of not finding the toothbrush or removing the cap from the toothpaste may have resulted in task completion.

The use of the general cue "Check your appearance in the mirror" in the dressing task provided potential for greater participant independence. It allowed participants to discover if some part of their appearance needed attention. The general cue worked well in the dressing task. All participants checked their appearance in the mirror, including many who had missed some step, such as turning down a collar, and they adjusted their clothing accordingly. Several participants rotated their body so they could see their back in the mirror. However, some additional directives continued to be needed. These directives were usually to address the back of the participant: Often the back of the shirt was not tucked in, or the back of the collar was up. The types and numbers of messages given for the three self-care tasks are summarized in Table 4.

One of the first participants in the oral care task needed to have some of the messages repeated. He mentioned that the problem was not a matter of not being able to hear but rather that the short message was nearly finished before he realized he should be paying attention. Following this comment, a tone was added prior to each message for the oral care task. The tone before a message alerted the participant that a message was coming. When asked, most participants stated that the tone was helpful; therefore, it was used throughout the remainder of the tasks.

A total of seven safety directives were given to three participants over the three tasks. Two demonstrated effects of stroke and used assistive devices for ambulation. Both needed messages involving safety in relation to walking or standing balance. Two individuals needed the directive to turn off the tap. Participants performed the dressing task while standing. However, on one occasion a participant was demonstrating such difficulty walking to the task area that she was asked to perform dressing in a seated position for safety. 
TABLE 4 Dressing: frequency of cues by task and type

\begin{tabular}{|c|c|c|c|c|c|c|}
\hline & $\begin{array}{c}\text { Total } \\
\text { messages }\end{array}$ & $\begin{array}{l}\text { Directives }^{\mathrm{a}} \\
\text { (or general } \\
\text { cues/directives) }\end{array}$ & Queries & Answers & $\begin{array}{l}\text { Repeated } \\
\text { messages }\end{array}$ & No response \\
\hline \multicolumn{7}{|l|}{ Drink of water } \\
\hline Frequency & 138 & 23 & 25 & 4 & 2 & 4 \\
\hline Range/trial & $1-5$ & $0-1$ & $0-2$ & $0-1$ & $0-1$ & $0-2$ \\
\hline Mean/trial (49 trials) & 2.81 & .47 & .51 & $<0.1$ & $<0.1$ & $<0.1$ \\
\hline \multicolumn{7}{|l|}{ Oral care } \\
\hline Frequency & 46 & 25 & & & 3 & 1 \\
\hline Range/trial & $1-8$ & $0-6$ & & & $0-3$ & $0-1$ \\
\hline Mean/trial (16 trials) & 2.9 & 1.6 & & & $<0.1$ & $<0.1$ \\
\hline \multicolumn{7}{|l|}{ Dressing } \\
\hline Frequency of use & 42 & $12 / 12$ & & & 4 & 2 \\
\hline Range & $1-5$ & $0-1 / 0-3$ & & & $0-3$ & $0-1$ \\
\hline Mean/trial (15 trials) & 2.8 & $.8 / .8$ & & & .29 & .14 \\
\hline
\end{tabular}

ancludes safety directives.

\section{Research Question 3}

The need to deliver cues was based on comments and questions from participants and visual inspection of the performance via the monitor. To develop a computerized system to deliver cues "as needed" would require the system to have the following capabilities:

- Input the questions or comments of the participant

- Determine how much water was consumed from a glass

- Determine if the tap was turned off at the end of the task

- Determine if all surfaces of the teeth had been cleaned

- Determine if the collar is down, shirt is tucked in, buttoning done correctly

- Determine if an assistive device for ambulation was being used

- Identify potentially dangerous situations and provide safety cues

\section{Research Question 4}

The drinking water task data were used for comparison for this question, as there were a greater variety of conditions between human and synthesized voice cues. Human voice cues in this task included live cues via intercom and prerecorded cues, and both types used a female voice. The synthesized voice cues contained both a male and a female voice. Comparison of individual performance revealed that three participants required slightly fewer cues with the human voice (one of these was hearing impaired). Additionally, five participants required slightly fewer cues with the synthesized voice, and three participants showed no difference. There was no difference between the three "voices" on number of repeated cues and cues with no response. At the end of all of the drink of water trials, participants were asked which "voice" they preferred. They were reminded of the human female voice, the synthesized female voice, and the male voice. Most stated the male synthesized voice was the easiest to hear, although several said it didn't matter.

\section{Research Question 5}

Early in these trials, it was noted that participants were not looking at the visual cues on the monitor. As observation continued, investigators noted that the monitor was never viewed. Participants were able to complete prompted tasks with the verbal cues available, and unsuccessful attempts to complete the tasks were the result of situations that came up for which there were no cues. 


\section{Research Question 6}

The success rate of trials demonstrated that participants in this MMSE range were able to complete the task with machine prompting at an overall rate of $86.4 \%$. The need for cognitive assistance in tasks was highly individual and did not appear to be closely related to MMSE or FIM scores in these participants. However, when MMSE scores were grouped by those with scores of 16 or below compared to those with scores above 16 , the group with the lower scores tended to need more machine prompts and human intervention. FIM scores were not related to the number of cues needed (Table 5).

Participants with effects of stroke needed more safety directives than the other participants and in one case needed more directives than those with a lower MMSE score. Participant E required more cognitive assistance than the others. This participant required the second highest number of directives in the drink of water task and the most directives in both the oral care and dressing tasks. This participant also needed the most safety directives, and these directives were primarily related to improving standing balance. Participant $\mathrm{K}$ needed a safety directive to use a walker during the drink of water task. This was the only participant who needed a safety directive in this task.

\section{DISCUSSION}

The results of this study suggest that independent of caregiver's reports of level of assistance needed for tasks, participants were largely able to complete the tasks with machine-delivered cognitive assistance. The FIM score for this level of assistance is a 6, or independence with the use of an assistive device. Caregivers reported that participants needed to be presented with liquids during the day, and some were coaxed to drink. Given appropriate messages, participants were able to get themselves a drink and consume at least 4 ounces of water $85 \%$ of the time. Although oral care is only one aspect of grooming, it appeared that two caregivers were providing the appropriate level of assistance-supervision. Three participants reported to be independent in grooming seemed to benefit from additional directives. In dressing, three participants who were reported to need minimum or moderate assistance were able to perform the task with machinedelivered cognitive assistance alone.

There are many possible reasons caregivers provide more assistance than is necessary such as the following: faster to help, misunderstanding ability to perform tasks, and enjoyment of or interpersonal need to provide assistance. Some caregivers may not realize that the care receiver would benefit from supervision. One participant in the study was given little assistance from the caregiver, while this participant's caregiver complained to investigators about poor task performance. The results support the notion that situationally aware, machine-delivered cognitive assistance could supplement caregiver assistance as well as increase independence in some tasks (Mihailidis \& Fernie, 2002). Mihailidis and Fernie (2002) also noted that amounts of cues given are reduced when prompting is done in a smart environment because cues are

TABLE 5 Individual summary of directives compared to FIM and MMSE

\begin{tabular}{|c|c|c|c|c|c|c|c|c|c|c|c|}
\hline & \multicolumn{11}{|c|}{ Participant } \\
\hline & $A$ & B & $C$ & $\mathrm{D}$ & $E^{a}$ & $\mathrm{~F}$ & G & $\mathrm{H}$ & I & $\mathrm{J}^{\mathrm{a}}$ & $\mathrm{K}^{\mathrm{a}}$ \\
\hline MMSE & 12 & 13 & 14 & 15 & 16 & 16 & 18 & 18 & 19 & 19 & 20 \\
\hline \multicolumn{12}{|l|}{ Drink } \\
\hline Mean directives & 1 & 0 & .8 & .25 & .63 & .25 & .5 & 0 & .25 & .125 & .5 \\
\hline \multicolumn{12}{|l|}{ Brush } \\
\hline Mean directives & 1.3 & & 2 & 2 & 2.8 & & 0 & .5 & & 0 & \\
\hline Mean safety & 0 & & 0 & 0 & .8 & & .33 & 0 & & 0 & \\
\hline FIM grooming & 7 & & 4 & 7 & 5 & & 5 & 7 & & 5 & \\
\hline \multicolumn{12}{|l|}{ Dress } \\
\hline Mean general cues & 1 & .66 & & & 1 & 1 & & .33 & 1 & & \\
\hline Mean directives & .25 & 1.6 & & & 3 & 1 & & .66 & 0 & & \\
\hline FIM dressing & 5 & 3 & & & 5 & 4 & & 5 & 5 & & \\
\hline
\end{tabular}

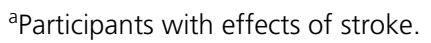


more judiciously used. Additionally, Kobayashi and Yamamoto (2004) found that if caregivers stray from the dressing task when assisting with dressing, the task takes longer. Machine-delivered prompting could keep the person's usual dressing routine more consistent.

The need for cognitive assistance was highly individual. It is possible that well-developed habits or lack of the same could also be a factor in the amount of cueing needed. Well-established habits continue to support self-care activities in the moderate range of dementia. The overall success rate for participants with MMSE scores from 12-20 suggests that further work should be done to determine if individuals with lower cognitive function would be able to respond to machine-delivered cueing. Cognitive function is a dynamic condition that changes throughout the day and can decline under stress, illness, fatigue, and other conditions. Participants with the highest MMSE scores demonstrated the need for occasional directives. Due to the diminished sense of thirst in elders (Chiappelli et al., 2002; Chalmers, Carter, \& Spencer, 2002), it is likely that those with mild dementia or no dementia would benefit from the start directive "It is time to take a drink of water." Individuals with lower MMSE were able to complete a prompted task, suggesting that people in what is considered the severe range of dementia might also be more independent with machine-delivered cognitive assistance.

Participants with dementia had no difficulty understanding the synthesized voice cues, responding equally well to human recorded voices. However, most participants stated that they preferred the male synthesized voice. People with mild hearing loss can hear the lower tones of the male voice better, which could explain the preference for the male voice.

When fully developed, the machine-based cognitive assistant will need to be able to sense a number of factors. Some information could be gathered using a voice recognition system and simple low-profile sensors. Sensors already exist for detection of water left on and water level. For participants who use assistive devices for safety such as a walker or cane, a method to detect whether or not the device is moving in relation to the participant may be more challenging but possible. More complex systems will be needed to detect the subtle actions in brushing teeth and dressing. This will include the capability of determining the orientation of an object in space. A precise method will be needed to detect such things as correct buttoning and collar position.

Participants did not utilize visual cues presented on the monitor in the oral care task. This could be because the monitor was to the right and about at sink level and therefore not in clear view as they looked in the mirror. However, since participants were able to successfully perform the task without reliance on visual cues, this suggests that they may not be needed. Persons with dementia who also suffer from receptive language problems might be better candidates for visual cues.

This study included three persons with dementia who also had effects of stroke. While these individuals were also able to complete the tasks, two of these participants needed safety directives related to safe ambulation or standing balance. Since vascular dementia is the second leading cause of dementia, it is important to include these individuals in dementia-related studies, but extra considerations for safety may be necessary.

\section{LIMITATIONS}

Limitations of this study include the small number of participants and trials, intrusiveness of setting up the equipment, the lack of familiarity of objects and contexts for self-care activities in the day centers, different forms of prompting from task to task, a possible learning effect throughout the course of the study, and the willingness and affability of the participants. While the drink of water task had the largest number of participants and trials, the numbers for the brushing teeth and dressing tasks were low.

For the two participants who performed trials in their own homes, the familiar environment and objects were ideal. However, the precursor to trials conducted in the home was two investigators arriving with a variety of technical equipment that needed to be placed and plugged in. This process may have had a priming effect, as the participant knew the investigators were there to conduct trials and the location and set-up of equipment suggested what task would be done. Initially, the study was to be performed with each participant in his or her own home. However, many caregivers were unavailable for trials in the home and expressed a preference for holding the trials while the person with dementia was attending a day program. Following the first two in-home trials, the remainder of the trials were held at day program centers. 
The tasks presented in the day program centers were more standardized due to the same environment being used for a number of participants. This setting eliminated the need for the more individual problem solving that occurred in the home environment. Another aspect of the task involved the set-up. In the day center, set-up was usually accomplished while participants took part in routine group activities. However, two of these participants, upon seeing the investigators arrive, would abandon their activity and approach the investigator or proceed to the area where the trials were conducted. This again represents a priming effect that would not occur if the technology were embedded in the home environment. While the setting at the day centers was familiar, oral care and dressing tasks were not performed at the day centers and were therefore novel in this context. Beverages were generally offered to the clients three times a day by staff; however, initiating getting a drink was novel. Staff reported that no clients initiated getting a drink, although a drinking fountain and kitchen were clearly visible to clients. The pitcher of water, glass, toothbrush, drinking cup, toothpaste, and the mirror were provided by the investigators and were also novel in these situations.

Based on findings from Research Questions 2 through 5, the way prompts were delivered was changed over the course of the study. Some types of cues were not used in every trial because it became increasingly difficult to schedule sessions with participants due to participant illness, day center activities, and so forth. Therefore, we narrowed the focus of our cue delivery based on how participants reacted in earlier trials. For example, we did not continue to use the female synthesized voice after learning that most participants preferred the male voice. We did not use pictorial cues for the dressing task because participants did not respond to pictorial cues in the oral hygiene task.

A learning effect may have also occurred during the course of the study since the number of cues required for the participants to complete the task decreased even though the complexity of the task increased (from the oral hygiene task to the dressing task).

The participants who agreed to take part in this study in general had pleasant dispositions and a good relationship with the investigators. The participants were pleased with their role of volunteering for a study with university investigators. This awareness of the special nature of the project and willingness to participate may have prevented the reactions possible when technology is embedded in the environment. These problems could include not wanting to interrupt their activity to perform a task as directed by a voice on a speaker or not hearing the speaker because of the volume on the TV. Additionally, it is not known how participants would respond over time. Would the routine nature of the messages be ignored once the novelty wore off, or might the messages become annoying to the participants? These and other longterm effects were not studied.

\section{CONCLUSION}

Participants were able to complete the tasks with machine-delivered cognitive assistance $86 \%$ of the time for the three tasks collectively. In addition to the start directive, most participants needed additional directives to accomplish the goal of the task, although with varying frequency. Overall, participants responded equally well to human voice and synthesized voice messages. Participants expressed either a preference for the male synthesized voice or no preference for the "voice" used.

The positive response from these participants with moderate dementia suggests that developing technologies that can be embedded into a "smart" or aware environment is worth pursuing. The need for personal caregiver assistance will not be eliminated. However, this study demonstrates that providing an effective alternative to caregiver assistance in some tasks could lessen caregiver burden and improve the independence of people with dementia.

Further research would be useful to determine the base and ceiling of cognitive abilities at which people with dementia would benefit from machine-based prompts, determine what type of participant (if any) would benefit from visual prompts, develop and test the technologies that would sense participants' progress in task performance, and expand the number of self-care activities included in machine-based cognitive assistance.

\section{ACKNOWLEDGMENT}

This is a publication of the Rehabilitation Engineering Research Center on Technology for Successful Aging, funded by the National Institute on Disability and 
Rehabilitation Research of the Department of Education under Grant H133E010106. The opinions contained in this article are those of the grantee and do not necessarily reflect those of the Department of Education.

\section{REFERENCES}

Abraham, I. L. (2006). Dementia and Alzheimer's disease: A practical orientation. Nursing Clinics of North America, 41, 119-127.

Alzheimer's Association. (2007). Warning signs of Alzheimer's disease. Retrieved December 10, 2007, from http://www.alz.org/alzheimers_ disease_symptoms_of_alzheimers.asp

Alzheimer's Disease and Related Disorders Association. (1985). Understanding and caring for the person with Alzheimer's disease. Atlanta, GA: Atlanta Area ADRDA Chapter.

Beck, C., Heacock, P., Mercer, S. O., Walls, R. C., \& Vogelpohl, C. G. (1997). Improving dressing behavior in cognitively impaired nursing home residents. Nursing Research, 46, 126-132.

Butin, D. N. (1991). Helping those with dementia to live at home: An educational series for caregivers. Physical \& Occupational Therapy in Geriatrics, 9, 69-82.

Chalmers, J. M., Carter, K. D., \& Spencer A. J. (2002). Caries incidence and increments in community-living older adults with and without dementia. Gerontology, 19, 80-94.

Chiappelli, F., Bauer, J., Spackman, S., Prolo, P., Edgerton, M. Armenian, C., et al. (2002). Dental need of the elderly in the $21 \mathrm{st}$ century. General Dentistry, 50, 358-363.

Cummings, J. (1984). Dementia: Definition, classification, and differential diagnosis. Psychiatric Annals, 14, 85-89.

Doyle, P. M., Wolery, M., Ault, M. J., \& Gast, D. L. (1988). System of least prompts: A review of procedural parameters. Journal of the Association of Persons with Severe Handicaps, 13, 28-40.

Folstein, M. F., Folstein, S. E., \& McHugh, P. R. (1975). "Mini-mental state": A practical method for grading the cognitive state of patients for clinicians. Journal of Psychiatric Research, 12, 189-198.

Fricke, J., Unsworth, C., \& Worrell, D. (1993). Reliability of the Functional Independence Measure with occupational therapists. Australian Occupational Therapy Journal, 40, 7-15.

Gitlin, L., Corcoran, M., Winter, L., Boyce, A., \& Hauck, W. (2001). A randomized, controlled trial of a home environmental intervention: Effect on efficacy and upset in caregivers and on daily function of persons with dementia. Gerontologist, 41, 4-14.

Glickstein, J. (1997). Therapeutic intervention in Alzheimer's disease: A program of functional skills for activities of daily living and communication. Gaithersburg, MD: Aspen.

Kobayashi, N., \& Yamamoto, M. (2004). Impact of the stage of dementia on the time required for bathing-related care: A pilot study in a Japanese nursing home. International Journal of Nursing Studies, 41, 767-774.

Labelle, K., \& Mihailidis, A. (2006). The use of automated prompting to facilitate handwashing in persons with dementia. American Journal of Occupational Therapy, 60, 442-450.

Lévesque, L., Ducharme, F., \& Lachance, L. (1999). Is there a difference between family caregiving of institutionalized elders with or without dementia? Western Journal of Nursing Research, 21, 472-497.

Lo Presti, E. F., Mihailidis, A., \& Kirsch, N. (2004). Assistive technology for cognitive rehabilitation: State of the art. Neuropsychological Rehabilitation, 14, 5-39.
Mann, W. C., Karuza, J., Hurren, D. M., \& Tomita, M. (1993). Needs of home-based older persons for assistive devices: The University of Buffalo Rehabilitation Engineering Center on Aging Consumer Assessments Study. Technology and Disability, 2, 1-11.

Mesulam, M. M. (2000). Principles of behavioral and cognitive neurology. London: Oxford University Press.

Mihailidis, A., Barbenel, J. C., \& Fernie, G. (2004). The efficacy of an intelligent cognitive orthosis to facilitate handwashing by persons with moderate to severe dementia. Neuropsychological Rehabilitation, 14, 135-171.

Mihailidis, A., \& Fernie, G. (2002). Context-aware assistive devices for older adults with dementia. Gerontechnology, 2, 173-189.

Mihailidis, A., Fernie, G., \& Cleghborn, W. (2000). The development of a computerized cueing device to help people with dementia to be more independent. Technology and Disability, 13, 23-40.

National Institute on Aging. (2004). 2000 progress report on Alzheimer's disease: Taking the next steps. Retrieved May 11, 2004, from http:// www.alzheimers.org/pubs/pr2000.pdf

Nochajski, S. M., Tomita, M., \& Mann, W. C. (1996). An intervention study of the use and satisfaction with assistive devices by elderly persons with cognitive impairments. Topics in Geriatric Rehabilitation, $12,9-16$.

Olsen, R. V., Ehrenkrantz, E., \& Hutchings, B. (1993). Creating supportive environments for people with dementia and their caregivers through home modifications. Technology and Disability, 24, 47-57.

Paton, J., Johnson, K., Katona, C., \& Livingston, G. (2004). What causes problems in Alzheimer's disease: Attributions by caregivers. A qualitative study. International Journal of Geriatric Psychiatry, 19, 527-532.

Plassman, B. L., Langa, K. M., Fisher, G. G., Heeringa, S. G., Weir, D. R., Ofstedal, M. B., et al. (2007). Prevalence of dementia in the United States: The Aging, Demographics, and Memory Study. Neuroepidemiology, 29, 125-132.

Poole, J., Dunn, W., Schell, B., \& Barnhart, J. M. (1991). Statement: Occupational therapy services management of persons with cognitive impairments. American Journal of Occupational Therapy, 45, 1067-1068.

Pynoos, J., \& Ohta, R. J. (1991). In-home interventions for persons with Alzheimer's disease and their caregivers. Physical and Occupational Therapy in Geriatrics, 5, 83-92.

Reimer, M. A., Slaughter, S., Donaldson, C., Currie, G., \& Eliasziw, M. (2004). Special care facility compared with traditional environments for dementia care: A longitudinal study of quality of life. Journal of the American Geriatrics Society, 52, 1085-1092.

Rogers, J., Holm, M., Burgio, L., Granieri, E., Hsu, C., Hardin, M., et al. (1999). Improving morning care routines of nursing home residents with dementia. Journal of the American Geriatrics Society, 47, 1049-1057.

Rowe, M. A., \& Fehrenbach, N. (2004). Injuries sustained by communitydwelling individuals with dementia. Clinical Nursing Research, 13, 98-110.

Vagelpohl, T. S., Beck, C. K., Heacock, P., \& Mercer, S. O. (1996). "I can do it" dressing: Promoting independence trough individualized strategies. Journal of Gerontological Nursing, 22, 39-42.

Van Kooten, F., \& Koudstaal, P. J. (1998). Epidemiology of post-stroke dementia. Haemostasis, 28, 124-133.

Zarit, S. H., \& Zarit, J. M. (1982). Family under stress: Interventions for caregivers of senile dementia patients. Psychotherapy: Theory, Research, and Practice, 19, 461-471. 